Published by Faculty of Islamic Civilization Studies, KUIS

\title{
KAJIAN AWAL TERHADAP CINTA ILMU DAN KEPERIBADIAN UMMAH CEMERLANG DALAM KALANGAN MAHASISWA MUSLIM
}

\author{
Nazneen binti Ismail ${ }^{1}$, Syaidatun Nazirah Abu Zahrin² ${ }^{2}$, and Nurzatil Ismah \\ Azizan ${ }^{1}$
}

\begin{abstract}
${ }^{1}$ Faculty of Islamic Civilization Studies, International Islamic University College Selangor (KUIS), 43000, Kajang, Malaysia.

${ }^{2}$ Pusat Citra, Universiti Kebangsaan Malaysia. Email: syaidatun@ukm.edu.my

Corresponding Author: Nazneen binti Ismail. Department of Dakwah and Usuluddin, Faculty of Islamic Civilization Studies, International Islamic University College Selangor (KUIS), 43000, Kajang, Malaysia. Tel: (+60) 192360477. Email: nazneen@kuis.edu.my
\end{abstract}

\begin{abstract}
ABSTRAK
Institusi pengajian tinggi perlu bersedia untuk melahirkan graduan yang boleh berhadapan dengan cabaran revolusi industri dengan membuat perubahan terhadap kurikulum dan kaedah pengajaran dan pembelajaran. Seiring dengan ciri revolusi industri yang menggunakan teknologi secara maksima dan mengurangkan tenaga manusia, ia mempunyai kesan positif dan negatif. Oleh itu, dunia hari ini memerlukan modal insan yang berupaya mencorakkan revolusi ini agar lebih bermanfaat. Hasrat ini dapat dicapai dengan adanya peribadi yang cintakan ilmu dan mempunyai keperibadian ummah cemerlang. Kajian rintis ini lakukan bagi tujuan mengesahkan dan memeriksa kebolehpercayaan instrumen kajian yang digunakan bagi menilai tahap cinta ilmu serta hubungannya dengan keperibadian ummah cemerlang. Soal selidik ini terdiri daripada 60 item dan diedarkan kepada 73 mahasiswa Muslim di dua buah institusi pengajian tinggi. Dapatan menunjukkan instrumen kajian cinta ilmu memiliki nilai kebolehpercayaan yang tinggi bagi konstruk cinta ilmu dan keperibadian ummah cemerlang. Maka instrumen kajian ini adalah sah dan boleh dipercayai untuk digunakan dalam kajian yang akan datang. Kajian ini membuktikan keilmuan perlu digandingkan dengan keperibadian ummah cemerlang kerana ia mampu mengajak kepada kebaikan dan mencegah kemungkaran hasil daripada keimanan yang utuh dalam diri. Hasilnya, modal insan yang mempunyai keyakinan diri, seimbang dan cerdas terhasil sesuai dengan keperluan masyarakat masa hadapan.
\end{abstract}

Kata kunci: Cinta; Ilmu; Keperibadian; Ummah cemerlang; Revolusi Industri 4.0; Mahasiswa Muslim; Modal insan 


\title{
(A PRELIMINARY STUDY ON LOVE FOR KNOWLEDGE AND THE EXCELLENT UMMAH PERSONALITY AMONG MUSLIM STUDENTS)
}

\begin{abstract}
Higher institutions of learning must be prepared to produce future-proof graduates who can face industrial revolution challenges by transforming the core of curriculum as well as teaching and learning methods. As the industrial revolution maximizes the usage of technologies while reducing human capital, it has both positive and negative impacts. Therefore, human capital that is able to shape the industrial revolution is highly needed. This can be achieved by developing human capital with a love for knowledge and an excellent ummah personality. A preliminary study was conducted to confirm the reliability of the research instrument used to measure the level of love for knowledge and their relationship with the excellent ummah personality. The questionnaire consisted of 60 items was distributed to 73 Muslim students at two universities. The result shows that this research instrument has high reliability for the constructs of love for knowledge and the personalities of the excellent ummah. Therefore, this instrument is valid for subsequent studies. This study shows that knowledge should be united with the personalities of the excellent ummah because individuals with these best personalities and strong faith are able to invite others to do good deeds and prevent wrongdoings. As a result, the human capital who are confident, balanced, and more discerning formed as needed by the future society.
\end{abstract}

Keywords: Love; Knowledge; Personality; Excellent Ummah; $4^{\text {th }}$ Industrial Revolution; Muslim students; Human capital

Received: September 15, $2017 \quad$ Accepted: April 3, $2018 \quad$ Online Published: June 30, 2018

\section{Pendahuluan}

Revolusi Industri adalah fasa yang diukur berdasarkan perkembangan ilmu dan teknologi dunia. Hari ini, dunia telah memasuki fasa Revolusi Industri 4.0 yang ditandai dengan perkembangan dalam bidang automasi, robot, pangkalan data raya, kepintaran buatan dan pelbagai lagi bentuk kemajuan teknologi baru. Perubahan ini berkait rapat dengan keperluan kepada ilmu dan kemahiran yang membolehkan manusia mencipta nilai dalam sistem ekonomi global. Namun begitu, modal insan yang berdaya saing dan mampu berhadapan dengan perubahan ini masih kurang jika dibandingkan dengan populasi dunia (Global Human Capital Report, 2017). Sedangkan teknologi baru ini dijangka memberi kesan negatif kepada manusia dari segi memperlahankan fungsi mental kerana keterikatan mereka kepada teknologi (Ali Selamat, Rose Alinda Alias, Syed Norris Hikmi, Marlia Puteh \& Siti Hamisah Tapsir 2017; Wan Khairuzaman, Abdul Aziz, Mohd Shah \& Neng Sri Novi Fitri 2005).

Maka, kesediaan untuk belajar atau memperkasa kemahiran baru adalah kunci utama bagi generasi akan datang (Oliver, 2017) dalam menghadapi cabaran ini. Di samping itu, mereka perlu menyediakan diri untuk menonjolkan kelebihan dan kemahiran yang lebih ke hadapan berbanding mesin atau robot. Antara kemahiran yang penting ialah kemahiran penyelesaian masalah yang kompleks, pemikiran kritis 
Published by Faculty of Islamic Civilization Studies, KUIS

dan kreativiti di samping kecerdasan emosi dan daya kognitif yang fleksibel (Future of Jobs Report, 2016). Ini bertujuan mengimbangi masalah yang timbul kesan daripada teknologi seperti kekeliruan dalam menilai maklumat (Mohd Farid, 2016). Ciri-ciri yang dinyatakan oleh kajian ini merupakan sebahagian daripada pembudayaan ilmu pengetahuan (Wan Mohd Nor, 1995) seperti yang diamalkan oleh para ilmuwan Islam sepanjang zaman. Hasilnya, mereka dikenali sebagai tokoh yang memiliki keluasan ilmu dalam pelbagai bidang, pemikiran yang melangkaui zaman di samping mempunyai keperibadian yang tinggi. Kesemua ciri-ciri ini adalah bertitik tolak daripada motivasi diri sama ada dalaman mahupun faktor sekeliling.

Sehubungan itu, dalam usaha mewujudkan semula generasi hebat seumpama ini, kajian berkaitan cinta ilmu dan hubungannya dengan keperibadian terpuji diperlukan. Ini berdasarkan kepada kepentingan ilmu untuk digandingkan dengan keperibadian yang baik. Maka, kajian ini bertujuan untuk mengesahkan dan memeriksa kebolehpercayaan instrumen yang digunakan dalam menilai tahap cinta ilmu mahasiswa dan hubungannya dengan keperibadian ummah cemerlang. Tumpuan diberikan kepada mahasiswa kerana mereka tergolong dalam kelompok cendekiawan yang berada di universiti sebagai pusat kelangsungan tradisi ilmu (Zaini 2009).

\section{Konsep Ilmu}

Ilmu bermaksud pengetahuan dalam perkara dunia, akhirat, zahir dan batin (Kamus Dewan 2005). Keluasan takrifan ilmu menjadi ciri utama Islam yang berbeza dengan keilmuan menurut Barat. Perkembangan ilmu di Barat bermula selepas pemisahan golongan ilmuwan daripada agama sedangkan perkembangan ilmu dalam sejarah Islam adalah seiring dengan galakan dan perintah Allah SWT (Saeful 2007; Marzukai 1994; Zaini 2009). Malah, ilmu dalam Islam mempunyai hubungan langsung dengan keperibadian seperti yang dinyatakan oleh al-Attas (1981) bahawa tujuan ilmu adalah melahirkan manusia yang baik sesuai dengan ilmu itu sebagai sesuatu yang dapat menjelaskan tempat yang benar dan tempat bagi sesuatu, batasan dan kegunaannya, serta membimbing ke arah kebenaran.

Ilmu membentuk peribadi yang benar (Muhammad Musnizam, 2012; Asari, H. 1993) sebagaimana dinyatakan dalam al-Quran bahawa ilmu dikurniakan kepada mereka yang melakukan kebaikan. Firman Allah SWT dalam surah Yusuf ayat 22:

Maksudnya:

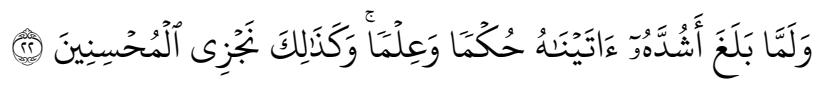

Dan tatkala dia cukup dewasa Kami berikan kepadanya hikmah dan ilmu. Demikianlah Kami memberi balasan kepada orang-orang yang berbuat baik.

Lebih utama lagi, hanya mereka yang berilmu akan mengakui keabsahan alQuran sebagai wahyu Allah SWT. Firman Allah SWT dalam surah al-Hajj ayat 54:

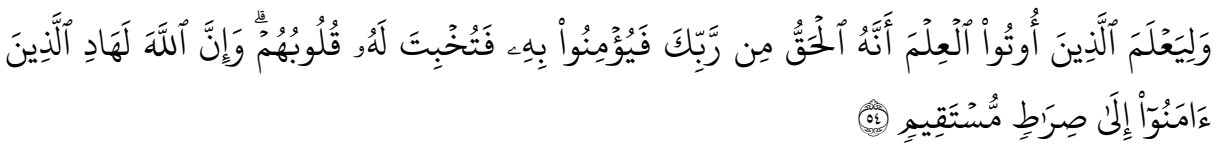


Maksudnya:

Dan agar orang-orang yang telah diberi ilmu, meyakini bahwasanya al Quran itulah yang hak dari Tuhan-mu lalu mereka beriman dan tunduk hati mereka kepadanya dan sesungguhnya Allah SWT adalah Pemberi Petunjuk bagi orang-orang yang beriman kepada jalan yang lurus.

Ini membuktikan bahawa hikmah Allah SWT mengurniakan ilmu kepada manusia supaya manusia beriman kepada Allah SWT, mengakui kehebatan-Nya dan mengamalkan ilmu yang menepati syariat. Keperibadian yang dibentuk atas asas ilmu yang benar akan menyelamatkan manusia daripada keperibadian yang buruk berpunca daripada kegagalan mengawal emosi dan kesilapan dalam menerima satu-satu perkhabaran. Firman Allah SWT dalam surah al-Hujurat ayat 6:
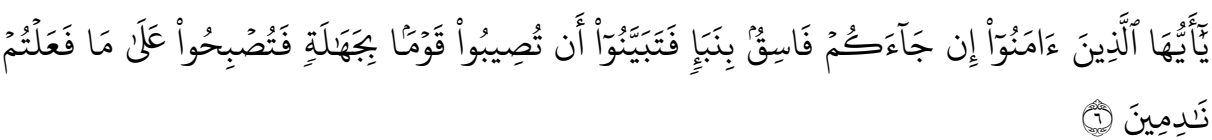

Maksudnya:

Hai orang-orang yang beriman, jika datang kepadamu orang fasik membawa suatu berita, maka periksalah dengan teliti agar kamu tidak menimpakan suatu musibah kepada suatu kaum tanpa mengetahui keadaannya yang menyebabkan kamu menyesal atas perbuatanmu itu.

Sehubungan itu, para penuntut ilmu turut dijanjikan dengan pelbagai ganjaran mulia di sisi Allah SWT seperti sabda Rasulullah SAW:

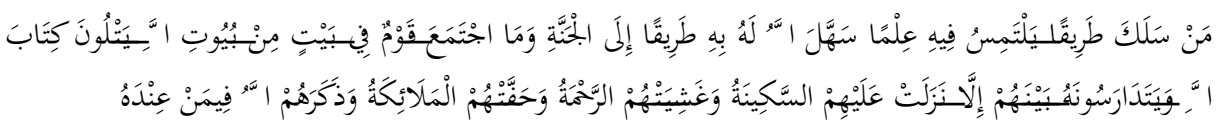

(Abu al-Husayn Muslim bin al-Hajjaj, Sahih Muslim, v. 13, h. 4867).

Maksudnya:

Barangsiapa yang menempuh satu jalan untuk menuntut ilmu maka Allah SWT akan memudahkan baginya jalan untuk ke Syurga. Tidaklah satu kumpulan berkumpul di dalam sebuah rumah di antara rumah-rumah Allah SWT, membaca kitab Allah (alQuran) dan mempelajarinya sesama mereka melainkan akan turun kepada mereka sakinah (ketenangan), diliputi ke atas mereka rahmat dan dinaungi oleh malaikat serta Allah SWT akan menyebut mereka pada malaikat yang berada di sisiNya.

\section{Ciri-ciri Pencinta Ilmu}

Seorang pencinta ilmu melazimi diri dengan adab-adab penuntut ilmu seperti yang telah dijelaskan oleh para ulama berdasarkan panduan al-Quran, hadis dan amalan salaf al-Salih. Antara adab-adab penuntut ilmu adalah (a) memiliki niat yang ikhlas, (b) bersungguh-sungguh membersihkan diri daripada perkara yang melanggar syariat, (c) merendah diri di hadapan guru, (d) menghormati guru, (e) membersihkan hati, (f) 
Published by Faculty of Islamic Civilization Studies, KUIS

fokus dalam majlis ilmu, menjauhi perkara yang melalaikan diri daripada tujuan ilmu, (g) memilih guru, (h) memilih sahabat yang soleh, (i) cekal dalam kesusahan semasa pencarian ilmu dan (j) minat mendalam terhadap ilmu (Muhammad Nuruddin 2012).

Selain itu, ciri-ciri pencinta ilmu juga dapat dilihat berdasarkan riwayat para ulama silam seperti Imam Abu Hanifah $(\mathrm{m} .150 \mathrm{H})$ yang memilih untuk mendalami ilmu fekah dan dikenali dengan sifat warak, memelihara penampilan diri dan tegas mempertahankan ilmu (Muhammad Abdulloh 2009). Keperibadian ini juga dimiliki oleh Imam al-Syafici (m. 204 H), seorang ulama yang dikenali dengan kepintaran dan keluasan ilmunya merentasi bidang. Kecintaannya kepada ilmu dibuktikan melalui pengembaraan ilmiah yang dilakukan serta pengiktirafan gurunya sendiri iaitu Imam Malik (Ibn Khallikan 1977). Selain itu, Imam al-Bukhari (m. 256 H) adalah tokoh utama dalam bidang hadis serta mempunyai sikap teliti yang sangat tinggi, kebergantungan hati kepada Allah SWT, melazimi ibadah dan amal soleh sepanjang hidup (Ibn Khallikan 1977; Muhammad Abdulloh 2009). Imam al-Nawawi (m. 676 H) juga mempamerkan kecintaan kepada ilmu melalui sikap tekun membaca dan berfikir mencari solusi bagi isu-isu yang rumit serta berani mempertahankan kebenaran di hadapan pemerintah (Muhammad Abdulloh 2009).

Dapat disimpulkan bahawa seorang pencinta ilmu memiliki ciri unik, adab dan penghormatan terhadap ilmu pengetahuan dan guru, sentiasa melazimkan diri dengan aktiviti-aktiviti keilmuan seperti mengembara, menuntut ilmu, membaca, berfikir, menelaah dan menulis, sentiasa bersedia untuk menyumbang kepada masyarakat, peka dengan keadaan sekeliling, bertegas dalam mengemukakan kebenaran dan sangat mengambil berat hubungan diri dengan Allah SWT melalui ibadah dan amal soleh.

\section{Keperibadian Ummah Cemerlang}

Peribadi dapat ditakrifkan sebagai sebagai personaliti. Ia berasal daripada kata akar Bahasa Latin "persona" yang bermaksud topeng yang digunakan oleh pelakon drama atau sandiwara (Abdul Mujib 1999). Keperibadian menggambarkan keunikan diri seseorang atau sebagai 'topeng' atau gambaran untuk mengenali seseorang. Perbahasan berkenaan peribadi dalam Islam sering dikaitkan dengan akhlak baik dan buruk seseorang. HAMKA (2017) menjelaskan bahawa peribadi adalah kumpulan sifat dan kelebihan diri seseorang termasuklah akal budi, cita-cita dan bentuk tubuh yang zahir. Menerusinya, seorang manusia dibezakan dengan yang lain. Tahap keperibadian seseorang bergantung kepada cara berfikir tentang sesuatu perkara. Kegagalan menerap nilai ilmu dalam diri menjadikan manusia tidak memiliki peribadi cemerlang (HAMKA 2017).

Ummah hari ini perlu disediakan dan dilengkapkan dengan jati diri yang sebenar sama ada sebagai pertahanan diri mahupun sebagai pencabar kepada asakan dari Barat selaku kuasa global. Umat Islam tidak sepatutnya sekadar tunduk dan merelakan diri dihanyut arus globalisasi. Tambahan pula, kecenderungan peringkat global menonjolkan kemajuan Barat telah menyebabkan umat Islam dilihat sebagai masyarakat yang gagal dalam membina suri tauladan yang berwibawa dan mampu memberikan inspirasi kepada muslim yang lain (Muhammad Ahsan 2000). Sedangkan umat Rasulullah SAW merupakan sebaik-baik umat. Firman Allah SWT dalam surah Ali 'Imran ayat 110:

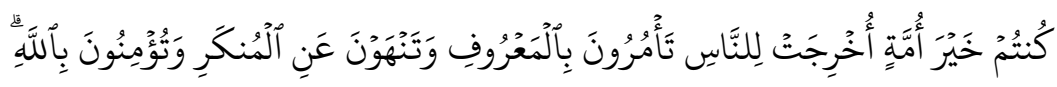


Maksudnya:

Kamu adalah umat yang terbaik yang dilahirkan untuk manusia, menyuruh kepada yang ma'ruf, dan mencegah dari yang munkar, dan beriman kepada Allah SWT.

Ayat ini menunjukkan hubungan antara kecemerlangan dengan usaha dakwah iaitu menyuruh kepada yang ma'ruf dan mencegah daripada kemungkaran. Strategi adalah penting bagi para pencinta ilmu untuk membina keperibadian cemerlang sehingga menjadi ikutan masyarakat sekeliling. Tambahan pula, sikap tidak prihatin akan kepincangan umat mengundang murka Allah SWT dan dijanjikan azab neraka (Mariam Abd Majid 2016). Kecemerlangan ummah diertikan dengan kejayaan memperolehi kebaikan di dunia dan akhirat. Kebaikan ini adalah hasil daripada keimanan mereka kepada al-Quran, keimanan kepada perkara ghaib, mendirikan solat, menafkahkan sebahagian harta dan meyakini hari akhirat. Mereka sentiasa mendapat petunjuk ketika hidup di dunia dan nikmat di akhirat. Firman Allah SWT dalam alBaqarah, ayat 2-5:

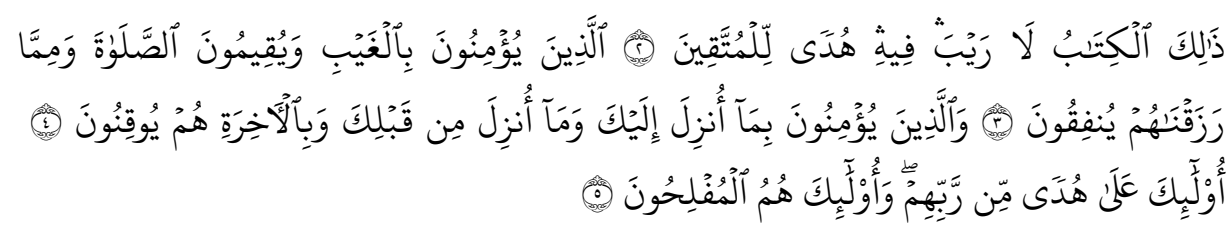

Maksudnya:

Kitab (al Quran) ini tidak ada keraguan padanya; petunjuk bagi mereka yang bertakwa, (yaitu) mereka yang beriman kepada yang ghaib, yang mendirikan shalat, dan menafkahkan sebahagian rezeki yang Kami anugerahkan kepada mereka, dan mereka yang beriman kepada Kitab (al Quran) yang telah diturunkan kepadamu dan Kitab-kitab yang telah diturunkan sebelummu, serta mereka yakin akan adanya (kehidupan) akhirat. Mereka itulah yang tetap mendapat petunjuk dari Tuhan mereka, dan merekalah orang-orang yang beruntung.

Al-Quran juga menggunakan istilah ulu al-albab dalam menggambarkan keperibadian yang seimbang dan sempurna. Golongan ini memiliki wawasan yang luas dan mempunyai ketajaman fikiran dalam menganalisis isu semasa, mereka juga menggunakan kelebihan yang dimiliki untuk mendekatkan diri kepada Allah SWT dengan cara mengingat (zikir) dan memikirkan (tafakkur) ciptaan-Nya (Muhammad Musta'in 2017; Eko Zulfikar 2017; Faszly Rahim et al. 2014). Golongan ini juga menggabung jalin antara al-Quran dengan fenomena alam sekeliling dengan tujuan memahami al-Quran berdasarkan alam dan kehidupan. Pemahaman al-Quran tidak lagi bersifat tekstual semata-mata tetapi dikembangkan seiring dengan percambahan ilmu pengetahuan (Faszly et al. 2014). Hasilnya, muncul rasa takut kepada Allah SWT dan ketakwaan yang kuat dalam dirinya. Di akhirat kelak, mereka dijanjikan balasan syurga 'Adn oleh Allah SWT (Muhammad Musta'in 2017; Eko Zulfikar 2017).

Ciri-ciri ini perlu digarap dengan baik oleh para pencinta ilmu melalui pengukuhan akidah dan ilmu dari masa ke masa. Ini bagi memastikan pemikiran umat dapat dikuasai dengan ilmu yang benar pada zaman berlakunya serangan pemikiran 
Published by Faculty of Islamic Civilization Studies, KUIS

secara terang-terangan sama ada oleh musuh luar mahupun dalam Islam sendiri (Mariam 2016; Nooraini 2009). Berdasarkan ciri ulu al-Albab, keperibadian seimbang adalah berasaskan kepada tiga perkara iaitu ilmu, iman dan amal soleh. Ketiga-tiganya disuburkan dalam diri melalui rasa cintakan ilmu pengetahuan di samping keimanan kepada Allah SWT dan keperibadian ummah cemerlang.

\section{Instrumen Kajian}

Kajian dilakukan secara kuantitatif bersifat keratan rentas (cross-sectional field survey) dengan menggunakan satu set borang soal selidik (Creswell, J.W 2003). Set soal selidik ini diedarkan kepada 73 mahasiswa di Universiti Kuala Lumpur (UniKL) dan Universiti Islam Antarabangsa Malaysia (UIAM). Ini kerana kajian ini bersifat rintis bagi menilai kesahan instrumen kajian soal selik yang diadaptasi daripada instrumen sedia ada, iaitu Instrumen Kajian Cinta Ilmu (Syaidatun Nazirah et. al. 2017) dan Inventori Personaliti Ummatik-UPI (Nooraini Othman 2008). Penentuan responden dan lokasi rintis ini dilakukan berdasarkan ciri-ciri yang menyerupai populasi kajian sebenar. Jadual 1 menunjukkan perincian berkaitan pembahagian soal selidik.

Jadual 1. Bahagian Utama Instrumen

\begin{tabular}{|c|c|c|c|c|}
\hline Bahagian & Item & & \multicolumn{2}{|c|}{ Sumber instrumen } \\
\hline$\overline{\mathbf{A}}$ & Cinta ilmu & $\begin{array}{l}\text { Soalan berkenaan ciri-ciri pencinta ilmu iaitu } \\
\text { cinta membaca, cinta penulisan, cinta } \\
\text { berfikir dan diskusi, cinta kebenaran dan } \\
\text { keadilan, cinta motivasi intrinsik, cinta } \\
\text { motivasi ekstrinsik }\end{array}$ & Syaidatun et & 1. 2017 \\
\hline B dan C & $\begin{array}{l}\text { Keperibadian } \\
\text { ummah } \\
\text { cemerlang }\end{array}$ & $\begin{array}{l}\text { Soalan berkenaan keperibadian ummah } \\
\text { cemerlang dari aspek ibadah, akidah dan } \\
\text { akhlak }\end{array}$ & $\begin{array}{l}\text { Nooraini } \\
(2008)\end{array}$ & Othman \\
\hline D & Demografi & $\begin{array}{l}\text { Latar belakang responden seperti umur, } \\
\text { jantina, jenis IPT, latar belakang pengajian } \\
\text { agama, peringkat pengajian di IPT, tahun } \\
\text { dan kursus pengajian }\end{array}$ & Penyelidik & \\
\hline
\end{tabular}

Bahagian A disesuaikan daripada Instrumen Kajian Cinta Ilmu (Syaidatun et. al 2017) yang mengandungi 26 item. Kesemua item ini ditambah tiga item berkaitan ilmu daripada instrumen Inventori Personaliti Ummatik (Nooraini 2008). Namun begitu, item-item kemudiannya disesuaikan dengan tujuan kajian dan cadangan daripada penilai instrumen menjadikan yang diguna pakai berjumlah 24 item dengan mengekalkan konstruk sedia ada iaitu cinta pembacaan, cinta penulisan, cinta berfikir dan diskusi, cinta kebenaran dan keadilan serta cinta motivasi intrinsik dan ekstrinsik. Skala yang digunakan ialah skala Likert yang diwakili oleh skala Sangat Setuju (5), Setuju (4), Sederhana (3), Tidak Setuju (2) dan Sangat Tidak Setuju (1).

Manakala Bahagian B dan C mengandungi pernyataan berkaitan sikap sebagai ummah cemerlang dari aspek ibadah, akidah dan akhlak. Item disesuaikan daripada Inventori Personaliti Ummatik (Nooraini 2008) yang mengandungi 30 item bagi konstruk ibadah dan 28 item konstruk amanah. Kemudian, hasil daripada cadangan para penilai, jumlah item dimodifikasi menjadikan yang diguna pakai adalah sebanyak 36 item sahaja. Bagi bahagian ini, pengukuran kekerapan digunakan menggunakan skala Sentiasa (5), Kerap kali (4), Kadang-kadang (3), Jarang-jarang (2) dan Tidak pernah (1). Bahagian D pula menanyakan maklumat latar belakang responden seperti 
umur, jantina, jenis IPT, latar belakang pengajian agama, peringkat pengajian di IPT, tahun pengajian dan kursus pengajian.

\section{Kesahan Instrumen Kajian}

Bagi instrumen kajian ini, dua bentuk pengesahan telah dilakukan iaitu kesahan muka dan kandungan. Bagi tujuan tersebut, pengkaji telah mendapatkan keizinan daripada pembina soal selidik sedia ada untuk mengguna pakai dan mengubah suai instrumen agar sesuai dengan tujuan kajian. Setelah keizinan diperoleh dan ubah suai dilakukan, pengkaji telah mengajukan soal selidik tersebut kepada empat orang pakar. Ia bertujuan untuk menentukan kesahihan butiran soal selidik. Pakar yang terlibat ialah Dr. Zetty Nurzuliana Rashed, dari Fakulti Pendidikan Kolej Islam Antarabangsa Selangor, Dr. Salasiah Hanin Hamjah dari Fakulti Pengajian Islam Universiti Kebangsaan Malaysia, Dr. Mahfuzah Mohamed Zabidi dari Universiti Teknologi Mara dan Dr. Azlina Abdullah dari Fakulti Pendidikan Universiti Kebangsaan Malaysia.

Pemilihan pakar ini adalah berdasarkan bidang kajian dan penulisan mereka merangkumi aspek integrasi ilmu, keperibadian Muslim, konsep ilmu dan kajian kuantitatif. Kemudian, bagi meyakinkan responden berhubung kerahsiaan identiti perkara ini dinyatakan secara tegas dalam pendahuluan soal selidik sebelum responden menjawab soalan yang disediakan. Ini adalah penting untuk mengelakkan berlaku bias dan tidak menggambarkan keadaan yang sebenar.

\section{Kebolehpercayaan Instrumen Kajian}

Data yang diperolehi dianalisis menggunakan perisian Statistical Package for Social Science bagi menguji ketekalan dalaman instrumen dengan menggunakan pekali Cronbach's Alpha. Perisian ini memiliki keupayaan analisis statistik yang tinggi dan sistem pengurusan data yang baik serta mudah dikendalikan. Bagi kajian ini, versi 20.0 digunakan berdasarkan kemampuan menganalisis yang tidak jauh berbeza dengan versi terkini. Hasil ujian ke atas pemboleh ubah cinta ilmu dan keperibadian ummah cemerlang adalah seperti dalam Jadual 2 dan 3.

Jadual 2. Kebolehpercayaan Instrumen Kajian

\begin{tabular}{lc}
\hline Bahagian & Nilai $\boldsymbol{\alpha}$ (rintis) \\
$\mathbf{N = 7 3}$
\end{tabular}


Published by Faculty of Islamic Civilization Studies, KUIS

Jadual 3. Ringkasan Analisis Kebolehpercayaan Instrumen

\begin{tabular}{lcc}
\hline Konstruk & Bilangan item & Nilai alpha \\
\hline Ciri pencinta ilmu & 24 & .905 \\
Keperibadian ummah cemerlang & 36 & .931 \\
\hline
\end{tabular}

Dapatan analisis menunjukkan instrumen ini mempunyai nilai Cronbach's alpha yang tinggi iaitu 0.905 dan 0.931 di mana kedua-duanya melebihi 0.70 . Nilai yang tinggi diperolehi kerana instrumen yang digunakan telah mengukur dengan konsisten apabila skor yang tidak berbeza apabila diuji pada masa yang berbeza dalam keadaan syarat dan keadaannya adalah sama. Maka, kebolehpercayaan item ini sebagai kebolehpercayaan yang baik. Kebolehpercayaan konstruk yang tinggi menggambarkan kewujudan konsistensi dalaman, iaitu semua pengukuran mewakili konstruk latent yang sama (Pallant, J. 2007; Lay Yoon Fah \& Chwee Khoo Hoon 2014, Hair et al. 2014).

\section{Kesimpulan}

Sistem pengajian tinggi hari ini merupakan medium pembudayaan cinta ilmu dalam kalangan mahasiswa. Hanya ilmu yang benar mampu menyumbang ke arah pembangunan masyarakat dan negara. Ini kerana ilmu mempunyai hubungan dengan keperibadian ummah cemerlang. Kedua-dua aspek ini penting dalam mendepani kemajuan teknologi dan lambakan maklumat. Ummah yang cemerlang dicirikan sebagai seimbang antara keperluan dunia dan akhirat sehingga mereka tidak terlalu tunduk kepada teknologi ciptaan manusia. Sebaliknya teknologi dijadikan sebagai alat dalam mencapai matlamat ilmu dan iman kepada Allah SWT. Hubungan antara cinta ilmu dan peribadi ummah ini telah dibuktikan melalui riwayat para ulama silam dan kontemporari. Justeru, dengan adanya instrumen kajian cinta ilmu yang disahkan dan memiliki kebolehpercayaan yang tinggi, kajian lanjut berkaitan tahap cinta ilmu para mahasiswa serta hubungannya dengan peribadi ummah cemerlang dapat dilakukan. Setelah itu, mekanisme bagi meningkatkan nilai ilmu para mahasiswa boleh dicadangkan ke arah penambahbaikan kredibiliti para peneraju negara masa hadapan.

\section{Rujukan}

Abd. Majid, M. (2016). Mendepani cabaran dunia moden: menyorot strategi ulama: Facing the modern world challenges: a review of Islamic scholars strategies. Al-Irsyad: Journal of Islamic and Contemporary Issues, 1(1), 5464. https://doi.org/10.53840/alirsyad.v1i1.35.

Abdul Mujib. (1999). Fitrah dan Kepribadian Islam Sebuah Pendekatan Psikologis. Jakarta: Darul Falah.

Abu al-Husayn Muslim bin al-Hajjaj. (2006). Sahih Muslim al-Musamma al-Jamic alSahih. Juz 13. Lubnan: Dar al-Jil li al-Nashr wa al-Tibacah wa al-Tawzic

al-Attas, S. M. (1981). Islam dan Sekularisme. K. Djojosuwarno (Terj.). Bandung: Penerbit Pustaka.

Ali Selamat, Rose Alinda Alias, Syed Norris Hikmi, Marlia Puteh \& Siti Hamisah Tapsir. (2017, 24-25 August). Higher Education 4.0: Current Status and Readiness in Meeting The Fourth Industrial Revolution Challenges. Kertas kerja dibentangkan di Seminar on Fourth Industrial Revolution (FIR 4.0), 
Kuala Lumpur. Diperolehi daripada https://www.mohe.gov.my/muatturun/awam/teks-ucapan...4.../file. Diakses pada 9 Januari 2018.

Anon. (2005). Kamus Dewan Edisi Keempat. Kuala Lumpur: Dewan Bahasa dan Pustaka.

Anon. (2016). Future of Jobs Report. Geneva: World Economic Forum.

Asari, H. (1993). The educational thought of al-ghazali: Theory and practice. Master of Art. Institute of Islamic Studies. McGill University.

Creswell, J.W. (2003). Research Design: Qualitative, Quantitative, and Mixed Methods Approaches. ( $2^{\text {nd }}$ ed.). California: Sage Publications, Inc.

Eko Zulfikar. (2017). Wawasan Al-Qur'an Tentang Ulu Al-Albab. Tesis Pascasarjana Ilmu al-Quran dan tafsir. IAIN Tulungagung.

Faszly Rahim, Zanaton Iksan, Oziah Othman, et al. (2014). Pemerkasaan Ulul Albab Melalui Modul STEM Bersepadu STEMind. The Online Journal Of Islamic Education. Special Issue of ICIEd2014. Hlm 1-12.

Global Human Capital Report. (2017). Geneva: World Economic Forum.

Hair, J.F, Black, W.C, Babin, B.J, Anderson, R.E. (2014). Multivariate Data Analysis. ( $7^{\text {th }}$ ed.). England: Pearson New International Edition.

HAMKA. (2017). Peribadi. Kuala Lumpur: PTS.

Ibn Khallikan, Muhammad bin Abu Bakar. (1977). Wafayat al-A $A^{c} y a n$ wa Anba' Abna' al-Zaman. Tahqiq: Dr. Hassan ${ }^{\mathrm{c}}$ Abbas. Beirut: Dar Sadir.

Lay Yoon Fah dan Chwee Khoo Hoon. (2014). Pengenalan kepada Pendekatan Kuantitatif dalam Penyelidikan Pendidikan. Kota Kinabalu: Penerbit UMS.

Marzukai Ibrahim. (1994). Budaya Ilmu: Perspektif al-Qur'an dan Pendidikan Malaysia. Tesis Sarjana Pengajian Islam, Universiti Kebangsaan Malaysia, Fakulti Pengajian Islam.

Mohd Farid Mohd Shahran. (2016). Ancaman akidah dan pemikiran Islam di alam siber. Dlm. Mohamad Zamri bin Mohamed Shapik (Pnyt.), Prosiding Seminar Undang-Undang Jenayah Syariah di Alam Siber. Cyberjaya: Jabatan Pengurusan Rangkaian Media, hlm. 1-16.

Muhammad Abdulloh Suradi. (2009). Lembaran Hidup Ulama': Warisan Ilmuwan Islam. Petaling Jaya: Hijjaz Records Publishing.

Muhammad Ahsan. (2000). Contemporary Global Ummatic Challenges and Future Vision: Human (Under-) Development and Clash of Civilisation. Journal of Political Studies, 1(2), 1-18.

Muhammad Musnizam Jaafar @ Mustafa. (2012). Konsep Berilmu Di Kalangan Guru Pendidikan Islam Satu Keperluan Dalam Membangunkan Modal Insan, Prosiding Seminar Antarabangsa Perguruan dan Pendidikan Islam (SEAPPI).

Muhammad Musta'in. (2017). Konsep Ulu al-Albab dalam a-Qur'an al-Karim dan Relevansinya dengan Pendidikan Islam. Latihan Ilmiah Fakultas Ilmu Tarbiyah dan Keguruan. UIN Syarif Hidayatullah, Jakarta, Indonesia.

Muhammad Nuruddin Marbu Al-Banjari Al-Makki. (2012). Martabat Ilmu \& Ulama. Terj. Mohammad Subki Abdul Rahman. Shah Alam: PSN Publications.

Nooraini Othman. (2008). The development and validation of the Ummatic Personality Inventory. Skudai: Penerbit Universiti Teknologi Malaysia.

Nooraini Othman. 2009. Keseimbangan Personaliti dan Akademik sebagai Teras Pembangunan Modal Insan. Didapati daripada http://eprints.utm.my/17876/1/Jurnal_UiTM-

Keseimbangan_Personaliti_dan_Akademik_sebagai_Teras_Pembangunan_M odal_Insan.pdf (diakses pada 19 Februari 2018). 


\section{Published by Faculty of Islamic Civilization Studies, KUIS}

Oliver, L. (2017). Can 'soft skills' save your job from the robots? Your best comments on the future of work. Didapati daripada http://www.weforum.org/agenda/future-of-work-community-soft-skills-jobsrobots (diakses pada 6 April 2018).

Pallant, J. (2007). SPSS: Survival Manual. England: McGraw Hill Open University Press.

Rahmat Aziz. (2007). Pendidikan Ulul Albab Pada Mahasiswa Universitas Islam Negeri (UIN) Malang. Progresiva: Jurnal Pemikiran \& Pendidikan Islam, 1, 307-320.

Saeful Anwar. (2007). Falsafah Ilmu al-Ghazali: Dimensi Ontologi dan Aksiologi. Bandung: Pustaka Setia.

Syaidatun Nazirah Abu Zahrin, Nur Hidayah Mohd Abd Malik, Shahizan Shaharuddin dan Mashitoh Yaacob. (2017). Pembinaan instrumen cinta ilmu dan kecemerlangan. Dlm. Syaidatun Nazirah Abu Zahrin, Nazneen Ismail dan Nur Hidayah Mohd Abd Malik (Pnyt.), Cinta Ilmu dan Kecemerlangan Transformasi Modal Insan (hlm. 20-49). Seremban: Itqans Enterprise.

Wan Khairuzzaman Wan Ismail, Abdul Aziz Mohd Amin, Mohd Shah Kassim dan Neng Sri Novi Fitri. (2005). Impak Penggunaan Automasi terhadap Prestasi Kerja Operator. Fakulti Pengurusan dan Pembangunan Sumber Manusia Universiti Teknologi Malaysia.

Wan Mohd. Nor Wan Daud. (1995). Penjelasan Budaya Ilmu. Kuala Lumpur: Dewan Bahasa dan Pustaka.

Zaini Ujang. (2009). Menghayati Budaya Ilmu: Faham Ilmu, Amalan dan Panduan (2 ed.). Skudai: Penerbit UTM.

\section{Biografi Penulis}

Nazneen binti Ismail, memulakan pengajian peringkat tinggi dalam jurusan Diploma Pengajian Islam (Usuluddin), Kolej Universiti Islam Antarabangsa Selangor. Kemudian, melanjutkan pengajian Ijazah Sarjana Muda di Universiti al-Azhar, Mesir dalam bidang Usuluddin pengkhususan Hadith wa Ulumuh. Setelah itu, beliau menyambung pengajian Sarjana Pengajian Islam di Universiti Kebangsaan Malaysia. Sejak 2008 hingga kini, beliau bertugas sebagai Pensyarah Usuluddin di Jabatan Dakwah dan Usuluddin, Fakulti Pengajian Peradaban Islam, KUIS. Merupakan ahli dalam beberapa kumpulan penyelidikan antaranya kajian bertajuk Analisis Faktor Tarikan Pelajar ke Program Sarjana Muda Pengajian Islam KUIS (2014-2015), Pendekatan al-Quran dalam Menangani Masalah Sosial: Kajian di Pusat Perlindungan MAIS (2015-2016), Tahap Kefahaman Belia Islam di Lembah Klang tentang Hak Kebebasan Beragama (2016-2017), Amalan Istitabah di Malaysia dari Aspek Sosio Perundangan (2016-2018). Selain itu, turut aktif membentang dan menulis kertas kerja dalam persidangan serta seminar peringkat kebangsaan mahupun antarabangsa yang dianjurkan. Bidang kajian beliau adalah tafsir, tasawuf, pemikiran dan kemasyarakatan. 